\title{
EXPERIENCE With A SMall UAV IN THE EngineERING DeSign Class at CAPIlano UniVersity - A NOVEl APPROACH TO FirST YeAR ENGINEERING DESIGN
}

\author{
Mark Wlodyka and Margaret Dulat \\ Division of Pure \& Applied Sciences, Capilano University, North Vancouver, B.C. \\ markwlodyka@capilanou.ca,mdulat@capilanou.ca
}

\begin{abstract}
Capilano University offers a very successful first-year Engineering Transfer and Engineering Transition Diploma program. A key learning experience for students of both programs is a one-semester Engineering Design course, in which the instructor leads the student through a practical design project, applying engineering design principles that are presented in the course. In 2014, a new project design theme was introduced, specifically working with small Unmanned Aerial Vehicles (UAVS). The teaching methodology combined both lecture and student led learning experiences. Student teams of 4 were provided a common assignment to carry out a field investigation using a UAV and video camera to simulate an industrial application. With experience gained on a PC based flight simulator, all teams successfully completed their designs, carried out their UAV flights and documented their results. Students developed project management and communication skills early in their engineering education. This innovative approach in first year provides students with immediate exposure to the practical limitations that constrain engineering design. The teaching methodology is expected to result in graduate engineers who have stronger skills in teamwork, communication, and design capability. This first year teaching methodology has shown significant promise as demonstrated through the quality of the design projects, as well as positive feedback from the students.
\end{abstract}

Keywords: Unmanned Aerial Vehicle, drone, simulator, project based learning

\section{INTRODUCTION}

Capilano University has been offering two very successful first-year Engineering Transfer programs. A key learning experience for students of both programs is a well subscribed one-semester Engineering Design course. The objective of this course is to lead the student through a practical engineering design project. By applying engineering design principles, students are able to investigate, design, build and test their own designs in a controlled learning environment. The design course attempts to start building student competence in all of the twelve fundamental Canadian engineering graduate attributes [2].

The purpose of this paper is to describe Capilano's approach to teaching engineering design, to share our experiences using UAVs in a design project, and to seek feedback from the community. We have experimented with different teaching strategies over the years, as well as different types of design projects, and we feel that the UAV project is particularly successful. We hope to provide some inspiration and guidance to other institutions who have contemplated using UAVs for design projects.

Project-based learning (PBL) has been used in classrooms since the early 20th century, following the work of John Dewey. It has recently been getting much attention, especially in STEM fields as a way of helping students to experience what STEM professionals actually do [3]. A simple definition of STEM PBL is "a well defined outcome with an ill-defined task". The ill-defined tasks require higher-order thinking skills, problemsolving, and more learning during the process of exploring possible solutions [3]. Project-based learning has been shown to be very effective when designed in a way that "with teacher support, [projects] marshal, generate, and sustain student motivation and thoughtfulness" [1]. To support this type of course design, students must perceive the project as interesting and valuable, and they must feel like they have the competence to participate in, and complete the project [1]. To achieve these goals, projects must be authentic, challenging, and provide closure by allowing students to actually create something. Students must have a choice in what work is done, and must be able to collaborate with others. Students need access to tools and information that will help them to develop the knowledge and skills necessary for solving the task. They must perceive failures as learning opportunities in an iterative process, 
where different solutions must often be tried before reaching a satisfactory one [1]. Capilano's approach of combining a hands-on design project with theoretical engineering design principles achieves the requirements for being an effective PBL course.

Introducing state-of-the-art design and fabrication technologies as part of an engineering design course in a first year engineering program is, to the authors' knowledge, relatively unique in Canada. Since there are many roadblocks to doing project-based design in year 1 , many institutions either do not offer such a course in year 1 at all [4],[5],[6],[7],[9], or introduce design concepts through case studies [8]. Some of these roadblocks might be large class sizes in year 1 at the larger institutions, or a lack of resources or support at the smaller ones. Capilano's teaching approach aims to build positive student learning experiences early in the students' engineering education.

Building on first year engineering courses that expose students to mathematics, physics, computer science, and computer aided engineering design tools, Capilano has designed the Applied Science 140 Engineering Design course that introduces real engineering problems early in the program. A key aspect of the student learning experience is to apply rapidly evolving engineering driven technologies (like UAVs) that provide not only a high degree of motivation for the students, but more importantly, exposure to a learning environment that develops many engineering design skills critical for success. These include teamwork, project management and planning, written and oral communication, and actual experience through the major stages of engineering design.

To enhance the student learning experience, the engineering design course explores teaching approaches beyond traditional lectures often used in first year engineering design. The challenge to the engineering educator is to provide engineering education that is not only current, using engineering technologies that support the desired engineering learning outcomes, but to provide an educational environment that motivates students to start on the journey of creating solutions to real engineering problems, and deepen their interest in building a career in engineering.

In past years, the instructors of engineering design at Capilano University have attempted various approaches to teaching engineering design, including focusing on case studies only, doing a design project on paper without implementation, and doing a design project with prototype implementation and execution of an experiment or competition. The latter approach has been the most difficult to administer and manage, but has also been the most effective in terms of student learning outcomes.

The teaching methodology selected combines formal lecture to introduce engineering design theory and principles, student led learning through oral presentations on specific topics associated with the design project, experience with computer simulation tools supporting practical aspects of design, test and verification, as well as hands-on, team-based design experiences and project management. In past years when students implemented a design project with a prototype, they competed with other teams to determine which design was best, in terms of specified criteria. For the year described in this paper, we decided to give them a real-world task to execute instead. While competitions can be fun, we decided that a realistic task and experiment would better motivate the students to consider what real engineers actually do, and therefore be more authentic and therefore motivating. We decided to use UAVs as a tool for executing the given experiment because these devices are increasingly prevalent, and a promising, affordable alternative for solving many problems that would otherwise require expensive, and difficult to manipulate machinery (as the example task used in the project). These also give students exposure to a mechanical device with an embedded microcontroller, and all the real-world limitations and consideration such devices entail.

Through student oral presentations during the course, the class was stimulated to explore a wide range of design concepts for implementation in their design projects.

\section{ENGINEERING TRANSFER PROGRAMS}

Capilano University has two engineering transfer programs designed for transfer into second year engineering at $\mathrm{UBC}$, though many students transfer successfully to other institutions offering engineering degrees as well. The "First-Year Engineering Program" is a typical engineering transfer program similar to those offered at other transfer institutions. It is intended for students with high achievement in mathematics, chemistry and physics, most of whom go into the program immediately after completing high school. The program allows students to complete the common first year engineering requirements within a small cohort of $35-40$ students before moving on to transfer to a chosen department within engineering in year two. It also allows North Vancouver residents to complete the first year of their engineering degree locally.

The "Engineering Transition Program" was designed for mature students who have been out of school for a number of years, and need a smoother transition back into the university environment. This program allows students to begin with preparatory courses in mathematics, chemistry, physics and computing science before they delve into the standard first year courses. In addition, students have the opportunity to complete a number of second year courses in mathematics and communications before transfer, so that they are better prepared for transfer into second-year engineering. These students will have a lighter course load both during the Transition 
program, and after transfer, as they have two years to complete the Transition program, and since they have some second year courses complete before transfer, their course load in the year after transfer may be lighter as well. Historically, one of Capilano University's strengths has been providing access to education to students who would not normally qualify for, or desire entry directly into a large, research-focused university. As such, the Engineering Transition program was developed to provide a path for students to begin pursuing a career in engineering, who otherwise encounter roadblocks in this pursuit. Although the program was originally intended for mature students, it also caters to recent high school graduates who do not have all the prerequisites required for entry into a standard first-year program.

\section{ENGINEERING DESIGN COURSE}

The engineering design course offered at Capilano University is a unique hands-on, project based course that gives students the opportunity to participate in all aspects of an engineering design, including investigation of a selected practical engineering problem, evaluation of potential design solutions, the impact of regulatory constraints, and the implementation of a student selected engineering solution, allowing the student to work through several stages of engineering design methodology. The course is taken simultaneously by students in the First-Year Engineering Program, and students in year two of the Engineering Transition program.

\subsection{Learning Objectives}

The learning objectives incorporated in the design course include the following:

a) To discuss and question engineering requirements and engineering design principles and process,

b) To work through all stages of team development and performance,

c) To communicate effectively through practice, preparing both oral presentations and written assignments,

d) To consider the importance of regulatory and legal requirements that constrain real life engineering design projects,

e) To prepare engineering drawings using software tools,

f) To value time and resource management, by setting schedules and milestones for a design project,

g) To value and use models, through computer simulation,

h) To use various rapid prototyping techniques for fabrication of student designs, i) To prepare an actual test plan that will be implemented by the student team, an integration procedure, and an evaluation of results.

\subsection{Methodology}

The course is based on a learning format that includes several methods, including the following:

a) Instructor led lecture material introducing the principles of engineering design and design methodology.

Formal lecture material on the principles of engineering design is presented, supplemented by question and answer during class to support student learning.

b) Class discussion of potential solutions to an industrial problem.

An industrial problem is presented to the students. This is followed by an open discussion of student-proposed solutions to the problem. Various pros and cons of potential solutions are discussed, ending with a concept that supports incorporation of a small drone as the technology of choice.

c) Student led learning through oral presentations of relevant design topic areas, selected by the instructor, or by the students themselves.

Students perform independent research in pairs, and present their findings in a 15 minute presentation to the class, discussing engineering concepts associated with various aspects of UAV technology and rapid prototyping technology.

d) Team based design and documentation of a custom solution to the selected engineering problem.

Working in teams of 4 , students develop design concepts, as well as project plans, which develop their project management skills to undertake a unique design. The design is documented in several chapters that are submitted during the course, culminating in a comprehensive final report, incorporating design details and test results.

e) Computer based simulation and training.

Prior to undertaking formal test flights, student teams practice on a computer based flight simulator, developing skills in piloting a small drone under various environmental conditions.

f) Fabrication using 3D printing.

Actual fabrication of prototype mechanical designs using 3D printing technology, followed by installation of their fabricated designs on the drone.

\subsection{Project Details}

In the Spring of 2014, a new project design theme was introduced in the engineering design course, specifically working with small Unmanned Aerial Vehicles (UAVs) or drones, as a teaching tool. The use of small drones, 
complemented in the following year by the introduction of rapid prototyping technology, provided a more comprehensive student design experience.

Each team of 4 students was provided a common assignment to carry out a design and field investigation project to simulate a real world application. The specific application covered the investigation of a potential cellular radio site. The students were required to determine obstruction clearance around the specific site, and document their results and conclusions. Project report outlines, schedules, and budgets were set up as guidelines for the students.

The selection of a specific drone and video camera as the technology of choice was determined collectively by the students. This was done early in the course, after discussion of various alternatives. The students discussed the pros and cons of various approaches, given budget and timeline constraints. The wide range of solutions evaluated were originally proposed by the students themselves.

The drone selected for the design course was the Steadidrone QU4D. This drone was selected based on overall performance and flight duration, payload and video camera carrying capability, ease of repair, compatibility with open source mission planning software, and finally, low overall weight, meeting Transport Canada UAV flight guidelines and licensing exemptions that allow university research. The video camera selected was the GoPro Hero 3+, a lightweight, HD camera, ideal for mounting on the QU4D motorized gimbal.

The students were also provided the opportunity to design, build, and integrate their own specific payloads, such as temperature sensors, into their project. The measurement of environmental conditions through custom design sensors, supported the teaching objective of valuing the importance and impact of environmental factors on engineering design. The students were also introduced to rapid prototyping technologies such as 3D printers, shown in Fig. 1, and laser cutters. Using AutoCAD Inventor Suite as 3D design software, the students designed their own payload mechanical support structures. An example mechanical structure is shown in Fig. 2. This and other structures were manufactured using a 3D printer, and integrated with the students' custom electronics. A sample of the sensor payload is shown in Fig. 3. An electronic payload sensor, fully ready for installation onto the drone, is shown in Fig. 4.

To complement instructor led teaching, the students researched, and presented to their peers, various aspects of system design approaches, application, and regulatory constraints impacting the use of the drone, and rapid prototyping technology. These student led presentations, often incorporating demonstration videos, led to more indepth discussion of the specific research topics presented.
An additional element added to the course was exposure to commercial computer simulators (AeroSIM $\mathrm{RC}$ ) prior to the flight-testing of their integrated payloads. All student pilots were required to pass a difficult simulator test, prior to obtaining permission to pilot the actual drone. This experience proved beneficial the past semester, as all teams successfully carried out their experiment without damage to either the drone or payload. All student teams commented on the usefulness of the simulator to ease their transition to piloting the actual drone.

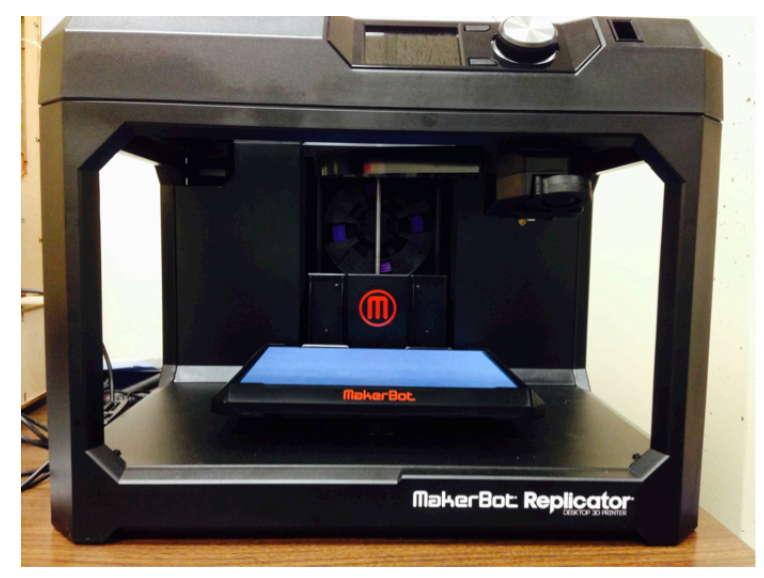

Fig. 1. 3D printer used in design course.

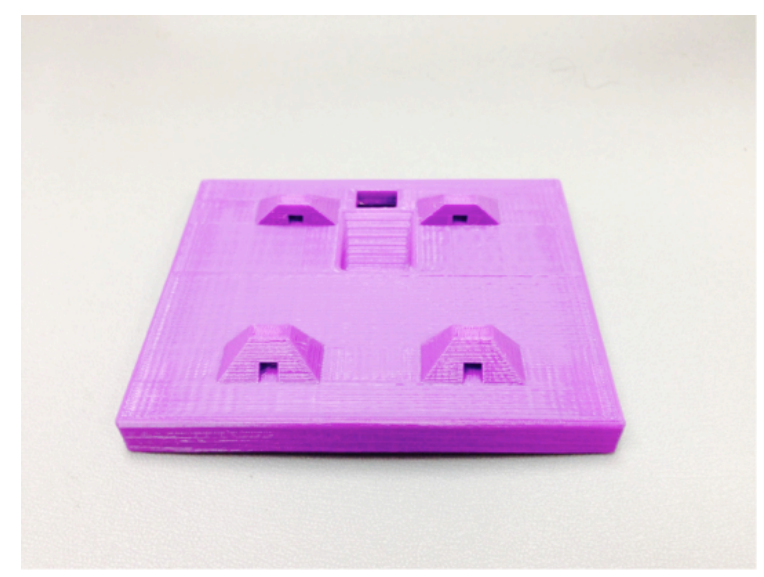

Fig. 2. Student designed payload cover. 


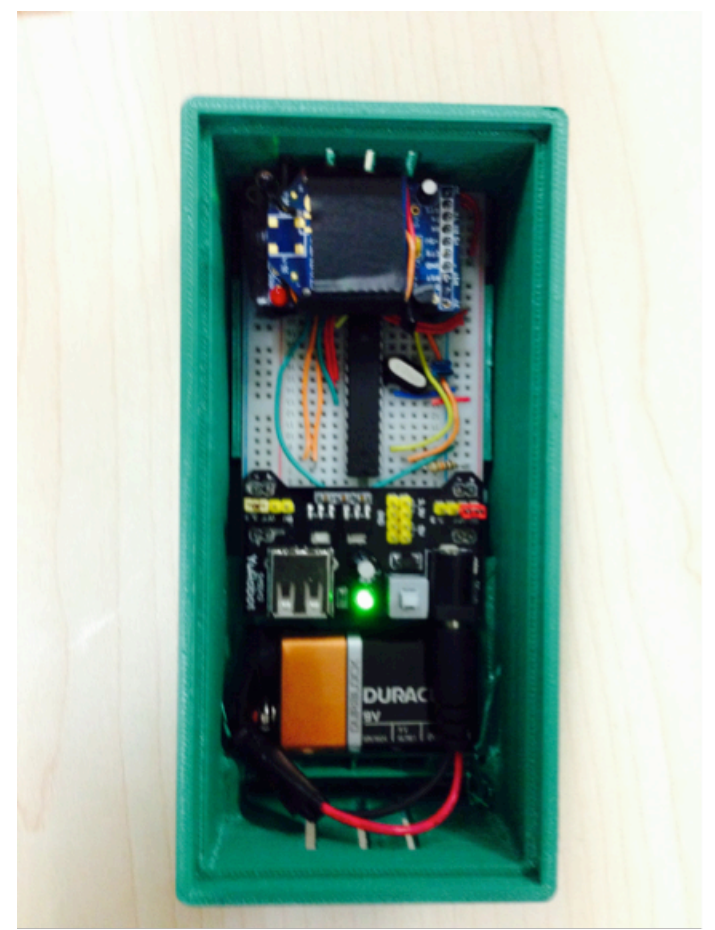

Fig. 3. Student designed electronic sensor.

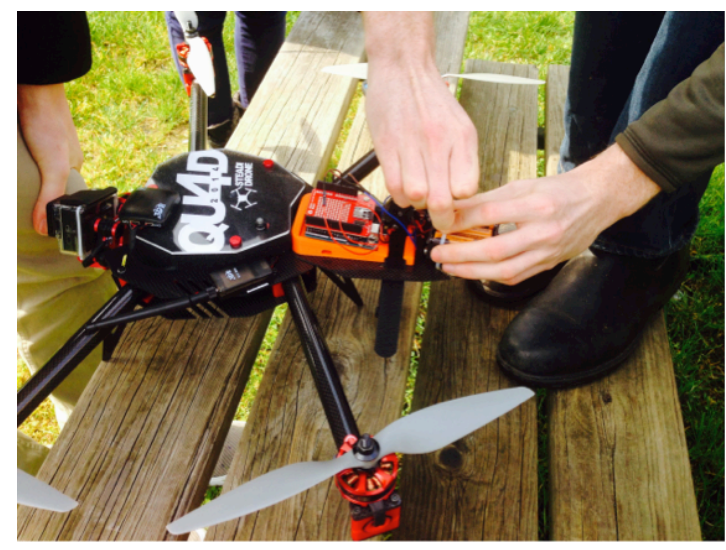

Fig. 4. Payload installation on QU4D UAV.

\section{CONCLUSION}

By working in teams from the outset, students developed project management and communication skills early in their engineering education. This innovative approach in first year provides students with immediate exposure to the practical limitations that constrain engineering design. The teaching methodology is expected to result in graduate engineers who have stronger skills in teamwork, communication, and design capability. The students will have had exposure to the 12 basic attributes of Canadian Engineering Graduates at a very early stage in their Engineering education.
This first year teaching methodology has shown significant promise as demonstrated through the quality of the design projects and final reports completed by the students, as well as positive feedback from the students themselves. The Capilano experience has found significant teaching benefits in the introduction of UAV technology as a learning tool early in engineering education. To date, all student teams have been successful in completing their designs on time and on budget, and have demonstrated their understanding of the objectives of the "industrial project".

A formal process to incorporate the results of students' assessment of the engineering design course is still under development, and will be incorporated in future classes. Student feedback is important for helping to improve the course content, and for monitoring the benefit of the overall teaching approach.

As department budgets permit, the course will be enhanced by the addition of other rapid prototyping technologies such as laser cutters and numerically controlled milling machines, to further support efficient fabrication of the student designs.

\section{Acknowledgements}

The authors acknowledge Dr. Antonio Cusanelli, Head, Pure and Applied Sciences Division for initiating the First-Year Engineering and Engineering Transition Programs, and for supporting the project-based learning and hands-on approach to teaching Engineering Design at Capilano University.

\section{References}

[1] Phyllis C. Blumenfeld, Elliot Soloway, Ronald W. Marx, Joseph S. Krajcik, Mark Guzdial, and Annemarie Palincsar, "Motivating Project-Based Learning: Sustaining the Doing, Supporting the Learning," Educational Psychologist, 26(3 \& 4), pp. 369-398, 1991.

[2] Canadian Engineering Accreditation Board, Accreditation Criteria and Procedures Report 2014, Canada: Engineers Canada, 2014 \{ISSN 1708-8054\}

[3] Robert M. Capraro, Mary Margaret Capraro, and James R. Morgan, STEM Project-Based Learning: An Integrated Science, Technology, Engineering, and Mathematics (STEM) Approach. Rotterdam, the Netherlands: Sense Publishers, 2013 (2nd ed.) \{ISBN: 978-94-6209-141-2\}

[4] Kwantlen Polytechnic University, "Engineering: Certificate Description", 2014/15 University Calendar. Available as of April 19, 2015 from http://www.kpu.ca/calendar/2014-15/sciencehort/engineering-cert.html 
[5] Langara College, "Engineering Transfer Program Curriculum", Programs and Courses.

Available as of April 19, 2015 from

http://www.langara.bc.ca/programs-and-

courses/programs/engineering/program-curriculum.html

[6] McGill University, "General Engineering Program Requirements", Programs, Courses, and University Regulations: Faculty of Engineering, Fall 2015 - Summer 2016.

Available as of April 19, 2015 from

http://www.mcgill.ca/study/2015-

2016/faculties/engineering/undergraduate/programs/bachelo r-engineering-beng-general-engineering-undeclare
[7] Thompson Rivers University, "Engineering Transfer Year One", Faculty of Science.

Available as of April 19, 2015 from

http://www.tru.ca/science/programs/engineering/yearone.html

[8] University of British Columbia, "Applied Science course descriptions", Vancouver Academic Calendar 2015/16. Available as of April 19, 2015 from http://www.calendar.ubc.ca/vancouver/courses.cfm?page $=$ co de $\&$ code $=$ APSC

[9] University of the Fraser Valley, Engineering Transfer Program Information Sheet, 2011. Available as of April 19, 2015 from http://www.ufv.ca/media/global/infosheets/Engineering.pdf 